\title{
Green Synthesis of Silver Nanoparticles Using the Mixture of Aqueous Extracts of Sedum praealtum and Origanum vulgare
}

\author{
L. Landeros-Páramo*1, G. Rosas ${ }^{1}$ \\ 1. Instituto de Investigación en Metalurgia y Materiales, UMSNH, Morelia, Michoacán, México. \\ * Corresponding author: landeros_jose_luis@yahoo.com
}

In recent years silver nanoparticles have generated interest for their unique properties about the macro scale given rise to research focused on the synthesis and modification of these nanomaterials [1]. Nanoscience through a variety of synthesis methods such as physical, chemical and green has studied the obtaining of nanoparticles. The latter offers the possibility of being economical and respectful to the environment by using plants including fruits, medicinal plants, shrubs, and even undergrowth [2]. From different parts of the plant are extracted the biomolecules antioxidant, and surfactants that work as reducing and capping agents, depending on the plant species are specific in type and quantity that leads to obtaining crystalline nanoparticles in a variety of shapes and sizes [3].

In this study, the synthesis of silver nanoparticles was carried out by chemical reduction of $\mathrm{Ag}^{+}$to $\mathrm{Ag}^{0}$ of silver nitrate $\left(\mathrm{AgNO}_{3}\right)$, using of aqueous extracts of Sedum praealtum and Origanum vulgare plants, as well as the mixture of them at room temperature. The extracts were prepared using the dried and ground leaves in a mortar; Subsequently, the infusion was carried out with each of the plants separately, mixing $100 \mathrm{~mL}$ of distilled water with $2 \mathrm{~g}$ of vegetable powder, heating to $60{ }^{\circ} \mathrm{C}$ for a period of $30 \mathrm{~min}$, and then filtering, the silver solution was elaborated at concentrations of $8,6,4$ and $2 \mathrm{mM}$ in deionized water. In the synthesis procedure, $5 \mathrm{~mL}$ of Sedum praealtum extract and $5 \mathrm{~mL}$ of silver salt solution were mixed in the first instance, generating a 1:1 volumetric ratio. In the same way, it was performed with Origanum vulgare plant extract. For the case of the synthesis combining the extracts, $2.5 \mathrm{~mL}$ of each extract and $5 \mathrm{~mL}$ of precursor salt was incorporated. The formation of nanoparticles was indicated by the color change of the reaction mixture from light brown to dark. The presence and size distribution were explored by UV-Vis (OceanOptics USB4000). The morphology, chemical analysis and distribution of the nanoparticles through scanning electron microscopy (JEOLJSM-7600F). Finally, the composition and crystal structure analyzed by X-ray diffraction (Bruker D8 Advance, DAVINCI Lynx eye). Fig. 1 shows the UV-vis spectra related to silver nanoparticles obtained by extracts of Sedum praealtum, Origanum vulgare and mixtures thereof these at $8 \mathrm{mM}$ salt, where specific signals between 400 and 500 $\mathrm{nm}$ are observed. In the UV-Vis spectrum, Sedum praealtum has an SPR peak at $490 \mathrm{~nm}$. Meanwhile, Origanum vulgare has an SPR peak at $480 \mathrm{~nm}$. Regard to the mixture of them the maximum is found at $480 \mathrm{~nm}$.

The three curves have a widened shape being more defined in the mix of both extracts, results that indicate that combining the biomolecules of both plants generate more uniform nanoparticles in size [4]. Fig. 2 corresponds to the XRD pattern that shows the indexed planes (111), (200), (220) and (311) which correspond to the angles $38^{\circ}, 44.5^{\circ}, 64.5^{\circ}$, and $77.5^{\circ}$, of the silver fcc, respectively in the extract mixture. Fig. 3a-c corresponds to the micrographs of the silver reduced by Sedum praealtum and Origanum vulgare and the mixture of them respectively. It is observed, that spherical and uniform Ag nanoparticles are obtained with Sedum praealtum extract. While, spherical, triangular and other morphologies with different size distributions synthesize through Origanum vulgare extract. However, by combining the plants, uniform nanoparticles are obtained in size and spheroid morphology. EDS 
analysis displayed in Fig. 3d illustrates the presence of elemental silver in the form of nanoparticles. These results show that the capacity of the molecules of Origanum vulgare plant to reduce is blended with the role of stabilization of the Sedum praealtum plant to give as an effect uniformity of size and shape of nanoparticles. These results mean an advance for the control of the syntheses of nanoparticles through the combination of active agents [5].

\section{References:}

[1] MS Dzul-Erosa et al., Materials Science and Engineering: C 91 (2018), p. 838.

[2] AK Keshari et al., Journal of Ayurveda and Integrative Medicine, https://doi.org/10.1016/j.jaim.2017.11.003(2018), p.

[3] S Raj, S Chand Mali and R Trivedi, Biochemical and Biophysical Research Communications 503 (2018), p. 2814.

[4] R Sankar et al., Colloids and Surfaces B: Biointerfaces 108 (2013), p. 80.

[5] V Hoseinpour and N Ghaemi, Journal of Photochemistry and Photobiology B: Biology 189 (2018), p. 234.

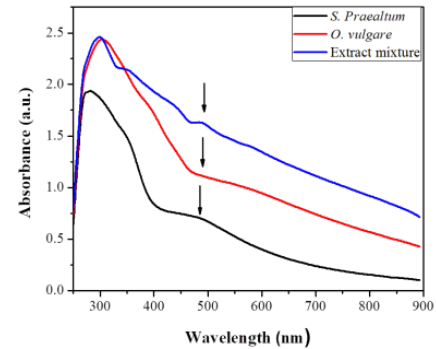

Figure 1. UV-Vis spectra of silver nanoparticles synthesized at $8 \mathrm{mM}$ of AgNO3 with different plant extracts.



Figure 2. X-ray diffraction pattern (XRD) of nanoparticles synthesized with the mixture of plant extracts.


Figure 3. Micrographs of scanning electron microscopy (SEM) of the silver sample at $8 \mathrm{mM}$ in a) Sedum praealtum, b) Origanum vulgare, c) mixture of plant extracts and d) EDS analysis of the sample of the mixture of plant extracts. 